\title{
PERMANECER HISTÉRICA: SEXUALIDADE E CONTINGÊNCIA A PARTIR DO CASO DORA
}

Vladimir Safatle

Vladimir Safatle

Universidade de São Paulo, Departamento de Filosofia, São Paulo/SP, Brasil.
RESUMO: Trata-se de retornar ao conceito freudiano de histeria através da releitura de seu caso mais famoso: o caso Dora. Espera-se, com isso, mostrar como o conceito freudiano de histeria não podeserabandonado pelosabermédico, pois eleexpõe, demaneira precisa, conflitosfundamentais no processo deconstituiçãosingular de identidades de gênero.

Palavras-chave: Histeria, sexualidade, psicanálise, gênero, contingência.

ABSTRACT: Staying hysteric: sexuality and contingence upon the Dora's case. This article aims to recuperate the Freudian concept of hysteria through a reinterpretation of Dora's case, his most famous clinical case of hysteria. I would like to show why medical knowledge must accept the Freudian concept of hysteria, mainly because Freud shows the nature of major conflicts in every singular constitution of gender identity.

Keywords: Hysteria, sexuality, psychoanalysis, gender, contingence.

DOI - http://dx.doi.org/10.1590/S1516-14982016003003

"Jouons donc cet amour aux dès."

(Guillaume Appolinaire)

\section{FALAR DE SEXO}

"Nesta história da doença (...) discute-se francamente as relações sexuais, osórgãos efunções sexuais são chamados por seu nome correto. Com isso, o leitor poderá se convencer, após minha exposição, que não recuei da discussão de tais assuntos em tal linguagem com uma garota. Devo então também me justificar desta acusação? Eu reivindico simplesmente os direitos do ginecologista ou ainda direitos muito mais modestos. Seria índice de estranha e perversa lubricidade supor que conversas parecidas seriam um bom meio de excitação sexual (FREUD, 1999, p.186) 
Estas colocações de Freud sobre sua análise com Dora são mais importantes do que parecem. Elas expõem, ao mesmo tempo, um modo de escrita e um regime de funcionamento da verdade. Pois se há algo que o século XX produziu foi a crença de que o falar franco sobre o que é da ordem do sexual implicaria, por um lado, lançar luz sobre o que somos e como nos relacionamos mas, por outro, transformar o que somos e como nos relacionamos. Como se a possibilidade do indivíduo moderno fazer a experiência de si mesmo como sujeito de uma "sexualidade" fosse dispositivo fundamental de sua autodeterminação. Digamos com clareza que seu reconhecimento como sujeito passaria necessariamente pela maneira com que ele é capaz de subjetivar uma sexualidade. Como dirá Alain Badiou:

“Deque Freud se sente responsável quanto à sexualidade? Ele pensa ser o agente de ruptura no real do sexo, para além mesmo da transgressão de alguns tabus morais ou religiosos? Tem a tremenda convicção de ter tocado no sexo, no mesmo sentido que, depois de Vitor Hugo, se tocou no verso?" (BADIOU, 2006, p.112)

As perguntas não poderiam ser mais claras. Trata-se de afirmar que, depois de Freud, ganha hegemonia um novo regime relativo à palavra que fala do sexual. Um modo de falar que modificaria profundamente nosso modo de ser, nosso modo de nos relacionarmos ao desejo e ao corpo. Michel Foucault insistirá neste ponto para afirmar:

\footnotetext{
"Se o sexo é reprimido, ou seja, votado à proibição, à inexistência e ao mutismo [como acreditamos que ele seria antes do aparecimento da psicanálise (nota e grifo nossos)], o simples fato de falar dele e de falar de sua repressão tem um ar de transgressão deliberada. Quem sustenta esta linguagem se coloca, até certo ponto, fora do poder; ele faz a lei tremer; ele antecipa, mesmo que apenas um pouco, a liberdade futura. Daí esta solenidade com a qual hoje se fala do sexo." (FOUCAULT, 1976, p.13)
}

Foucault insiste na continuidade entre a perspectiva freudiana e as "ciências das sexualidade" que aparecerão na segunda metade do séculoXIX. No entanto, é certo que Freud marca uma importante e influente inflexão capaz de explicar a existência, em nossa época: "de um discurso no qual o sexo, a revelação da verdade, a inversão da lei do mundo, o anúncio de um outro dia e a promessa de uma certa felicidade estão ligados" (idem, p.15). Discurso este que aparece na linha direta da reflexão psicanalítica sobre os modos de repressão da sexualidade.

Ou seja, teríamos então um modo de falar de sexo e uma crença de que tal modo poderia antecipar exigências de liberdade. Mas que modo é este do qual Freud se vê legatário? Ele se enuncia nesta inveja dos "direitos do ginecologista". 
Esta fala não pode ser vista, dirá Freud, como fala que porta lubricidade, interesse. Freud dirá que ela deve ser "seca e direta", dando aos órgãos sexuais seus nomes técnicos e comunicando seus nomes quando estes são desconhecidos pela paciente. Uma fala que descreve as perversões "sem indignação". Ou seja, como já disse Foucault, esta fala é uma vontade de saber baseada na submissão da sexualidade ao modo de descrição de uma scientia sexualis. Por meio desta submissão, a psicanálise teria produzido um imperativo de transformar o desejo em discurso, de recusar a ideia de que o que é da ordem do sexual possa ser acolhido por um silêncio indiferente.

É desta transformação a questão no caso Dora. Sua escrita é a escrita de uma exigência. Ao falar francamente sobre sexo com uma garota, Freud não apenas escuta. Ele lheensina como falar, em que condições seu desejo pode ser colocado em discurso, qual história ele deve contar, qual conflito ela deve assumir. Falar não é apenas liberar. Falar é também internalizar uma gramática do desejo. Assim, podemos ler o caso freudiano também como a história de um conflito. $O$ conflito que ocorre quando as relações sexuais, seus órgãos e funções são postos em determinado regime de "falar franco", são levados a assumir certas histórias e dinâmicas. Se assumirmos tal perspectiva, o caso Dora talvez aparecerá como um interessante relato de certa forma de resistência que não é apenas uma reação terapêutica negativa, mas a insistência da dificuldade em constituir uma fala sobre a sexualidade que seja capaz de dar voz aos arranjos contingentes que a sexualidade produz. A posição de Freud é aquela de quem fornece uma norma geral de fala. A posição de Dora é aquele de quem não a aceita completamente .É esta incompletudeem relaçãoà norma de fala fornecida por Freud que produzirá a ruptura do tratamento.

Freud afirma que o tratamento nos permite: "ter uma visão de conjunto (Uberblicken) consequente, compreensível e completa da história da doença". Pois: "se o objetivo prático do tratamento consiste em suprimir todos os sintomas possíveis substituindo-os por pensamentos conscientes, há ainda um outro, o objetivo teórico, que é a tarefa de curar o doente de todos os males da memória (Gedächtnisschäden)" (FREUD, 1999, p.175). Mas devemos colocar a questão: em que condiçõessepodeforneceruma história completa, consequenteecompreensível de uma doença psíquica? Qual é o preço para que a doença se transforme em uma "história"? E mais ainda: que tipo de história conta a histeria? Seria apenas a história da impossibilidade de um declínio bem-sucedido do Complexo de Edipo ou a história de uma sexualidade que não sabe como lidar com as contingências de suas construções? 


\section{O CORPO HISTÉRICO}

A fim de tentar responder a tais questões, lembremos de alguns traços maiores do caso. Dora era uma histérica de 18 anos levada a Freud por seu pai devido a uma intenção de suicídio, enunciada em uma carta, seguida de um acesso de desmaio. Ela apresentava sintomas de depressão, transtornos de caráter ealguns sintomas somáticos, como tosse nervosa, dispneia e afonia. Dora já apresentava transtornos neuróticos desde a idade de 8 anos (problemas respiratórios). Aos 12 , aparecem dores de cabeça, tosses nervosas e pigarreamento. As dores de cabeça desaparecem à idade de 16 anos, o resto persiste.

Com este quadro de sintomas, Freud procurará confirmar a presença de um conjunto de condições, enunciadas desde o Estudos sobre a histeria (1893-1895), para o aparecimento da histeria, como o trauma psíquico (que se organiza como um "corpo estranho" no interior do sistema de representações do sujeito), o conflito de afetos e a intervenção da esfera sexual.

Lembremos como a noção freudiana de trauma estava ligada à dinâmica ação/reação. Daí porque Freud falará que "a histérica sofre de reminiscências". Pois ela sofreria de lembranças traumáticas (em geral, ligadas à sexualidade) que não foram suficientemente ab-reagidas. Assim, podemos seguir a interpretação de Jean Starobinski:

"O distúrbio característico da histeria consiste em uma perturbação do mecanismo da resposta motora: esta, atrasada ou desviada, não pode ser efetuada adequadamente, pelas vias enotemponormais. Aoadotaresta concepção do comportamento histérico, Freud não se exclui da teoria bastante difundida que explicava a função cerebral a partir do modelo evidenciado pela experiência fisiológica do reflexo sensório-motor espinhal. O esquema do reflexo, para a época, é uma garantia de cientificidade." (STAROBINSKI, 2003, p.172)

Esta incapacidade de reação, que provoca a constituição de uma espécie de memória patológica, memória das reações não feitas e dos desejos não enunciados, será o índice principal de um evento traumático que espera resposta. Esta memória será o motor do sofrimento patológico portado pelo corpo histérico.

Levando isto em conta, tentemos reconstituir alguns momentos decisivos do caso Dora. A análise de Dora, que só dura três meses, se coloca inicialmente sob o signo da reivindicação dirigida ao pai. Dora reclama que o amor de seu pai lhe fora roubado pela ligação deste com uma amante, Guiseppina Zellenka ( a "Sra. K"). Como em uma espécie de troca, ele a ofereceu às assiduidades do marido da amante, o Sr. K.

Freud recua então à idade de 14 anos para encontrar uma cena envolvendo o Sr. Ke que poderia responder ao trauma que consolida o quadro histérico. 
Na ocasião, ele convidara Dora a ir à sua loja, após uma solenidade religiosa. Enquanto Dora esperava que o Sr. K fechasse a loja, ele a agarrou e a beijou na boca. Tomada de profundo desgosto, Dora desvencilhou-se dele efugiu por uma porta aberta. No entanto, ela nada diz sobre o incidente. Silêncio que indica ausência possível de reação. Um sintoma somático (uma alucinação sensorial) aparece: a pressão na altura do tórax. Freud deduz que tal pressão era a marca do sentimento da ereção do pênis do Sr. Kquando este a apertou contra seu corpo.

Note-se como, neste caso, a natureza traumática do incidente está ligada ao despertar da sexualidade na idade madura, assim como ao encontro de si na posição de objeto de desejo sexual do desejo masculino. Há um problema ligado à assunção da feminilidade que assombra a histeria. Isto permite definir a experiência traumática não apenas como experiência do aparecimento de uma quantidade de excitação sexual que provocou desgosto no paciente. Tratase sobretudo de afirmar que, na histeria, é impossível à mulher sustentar-se na posição feminina, ou talvez seja melhor dizer:é impossível à histérica lidar com osdesafios própriosatodaequalquermulherquesesustenta na posiçãofeminina.

Freud afirma que a excitação sexual que deveria aparecer nesta cena foi vivenciada por Dora como desgosto. Uma garota normal teria se excitado, alguém capazde saber oque fazercom suafeminilidade teria secomportadosem maiores problemas, diz Freud. Mas, a princípio, a posição de Freud parece insustentável. Afinal, tudo se passa como se ele recebesse em seu consultório uma garota que sofrera assédio sexual, não tendo ideia melhor do que tentar convencê-la deque, afinal de contas, ela está apaixonada por seu agressor. Note-se, no entanto, que a verdadeira ideia de Freud consiste em dizer que Dora não reage nem com uma excitação clara nem com um simples desgosto. A simples repulsa violenta ao assédio indicaria que ela nada quer do Sr. K. Mas isto não explicaria os sintomas somáticos como a pressão no tórax, nem a perpetuação da relação. Tais sintomas são, ao menos para Freud, a marca de uma reação contraditória onde desgosto e excitação parecem investir o mesmo processo. Desta forma, o problema da natureza traumática da situação vem do fato de haver algo de profundamente contraditório que impede a ação.

Tal contradição encontra sua raiz na explicação freudiana deste desgosto como incapacidade de a histérica idealizar os órgãos sexuais, retirando-os de sua função excremental, cuja atração deve ser objeto de um recalque orgânico. Esta sobreposição entre duas funções devalorcontrário (excitação sexual eexcrementos), assim como o déficit de idealização indica uma ambivalência insuperável entre desgosto e atração. Tal ambivalênciaé resultado direto de um recalque que não se realiza no caso da histeria. Ela não recalca a natureza aversiva dos órgãos sexuais através daquilo que Freud chama de "recalque orgânico" fundamentado 
no trabalho de valores morais como a vergonha, o que tem por consequência fragilizar uma organização da sexualidade centrada no primado genital.'

A este respeito, não escapa a Freud o fato de Dora ter um desgosto ligado à zona erógena bucal. Pois o corpo histérico é um corpo onde os prazeres específicos de órgão não se submeteram a uma experiência sexual centrada no prazer genital. Seu corpo é um peculiar corpo no qual as zonas erógenas e as pulsões parciais parecem não se submeter a uma representação da sexualidade ligada à genitalidade e, por isto, capaz de produzir a organização funcional de uma sexualidade em que seria possível a assunção de uma identidade de gênero.

O problema da corporeidade é central na histeria e explica por que sempre encontramos quadros histéricos com sintomas somáticos. Podemosmesmodizer que Dora é histérica porque: "tudo o que lhe acontece e lhe diz respeito começa a existir, para ela, por meio daquilo que fica marcado, como posições ou estados de seu corpo" (DAVID-MENARD, 1990, p.41). Para elaborar sua identidade, Dora coloca em cena seu corpo, um corpo fragmentado no qual certas regiões parecem extremamente sensíveis por absorver toda a história de seu desejo. Isto apenas retoma uma intuição primeira de Freud e Breuer a respeito do caráter hiper-sensibilizado do corpo na histeria. ${ }^{2}$

O relato de Freud nos permite perceber como, no caso de Dora, seus sintomas somáticos são ligados à oralidade (acesso de tosse, dispneia, asma nervosa, afonia). No fundo, eles revelam a inscrição, no corpo sexuado, de um modo de identificação e de demanda em relação ao pai (um grande fumante), o que não deixa deindicar a representação oral da relaçãosexual (felação) prevalentedevido à impotência paterna, assim como os prazeres de chupeteadora (Dora chupou o dedo até a idade de 4 a 5 anos) na sua primeira infância e que estabelecem o gozo em uma área de cumplicidade com o pai.

Desta forma, o vínculo irredutível de Dora em relação ao pai traduz-se em uma recusa em aceitar certa mudança no estatuto de seu corpo na qual o gozo oral deveria se submeter a uma organização genital. Insistir na prevalência de seu gozo oral é uma forma de continuar a ser a filha de seu pai, e não a mulher de um homem. É o esquema geral da doença mental como regressão que encontramos aqui. Mas note-se que este vínculo ao pai não indica necessariamente a ligação a um objeto, mas a um modo de gozo que Dora não quer abandonar, ou mesmo integrar. Desse modo, podemos dizer que, se o beijo do Sr. K foi tão aversivo, é porque ele não termina aí. Ao contrário, ele funciona como certo empuxo para Dora deixar

\footnotetext{
${ }^{1}$ Daí a afirmação de que: "a relação histérica à sexualidade é caracterizada pela iminente e insuperável ameaça de contaminação que o excremental coloca ao sexual" (GEYNSKEN \& VAN HAUTE, 2012, p.48).

${ }^{2}$ A este respeito, ver Geysken \& Van Haute, 2012, p.31.
} 
de vivenciar toda a história de seu desejo pela boca. A sensação do pênis ereto do Sr. K seria a prova deste fato. Daí porque o sintoma somático só poderia ser ligado a tal sensação.

\section{UMA OUTRA MULHER}

Se o problema da inscrição do corpo no interior de uma organização libidinal centrada na genitalidade pode aparecer como fundamento da histeria, isto nos explica por que a questão de gênero lhe é tão constitutiva. A histeria é uma patologia cuja questão central gira em torno da identidade de gênero, patologia que marca o sofrimento diante da assunção de um corpo marcado pela diferença sexual e sua genitalidade. Daí por que uma das características principais da histérica diz respeito ao modo de construir identificações que possam reforçá-la, por imitação, em uma posição feminina que aparece insistentemente em questão.

Sabemos como, desde os gregos, a histeria era uma "questão de mulheres, ou melhor, de parteiras" (TRILLAT, 1986, p.17). Hipócrates falava dos sintomas provocados pela "sufocação da matriz" e pela mobilidade do útero que, ao tocar outros órgãos como o fígado, provocaria reações como a perda de voz ea lividez. Para manter o útero em seu lugar, o médico grego prescrevia a relação sexual e a gravidez. Algo não muito diferente encontra-se em Platão que, no Timeu, compara o útero a um ser vivo possuído pelo desejo de procriar e que se irrita quando permanece estéril durante muito tempo, "causando toda variedade de doença" (PLATÃO, 1990, 91c). Ou seja, a articulação entre histeria e sexualidade mostra-se como uma das correlações mais antigas da história da medicina. Assim, mais do que um instaurador, Freud aparece como um peculiar restaurador, ao insistir na etiologia sexual da histeria. No entanto, em seu caso, Freud insiste em tal etiologia para mostrar a necessidade da condução da paciente à assunção do lugar social que poderia determinar sua sexualidade.

É pensando em tais questões que devemos entender a tendência freudiana em interpretar o que se dá entre Dora, o casal Ke seu pai a partir de um problema ligado à dinâmica das identificações. Vejamos este ponto com mais calma.

Dora sabe das relações entre seu pai e a Sra. K. Ela sabe também quão impossível era sua mãe não estar a par. No entanto, a figura materna aparece no caso marcada pelo desprezo do pai, pela falta de afeto em relação aos filhos, pela passividade e pela presença de sintomas obsessivos ligados à limpeza. Mesmo seu filho afirma que a presença da amante deve ser vista como uma dádiva, já que a mãe compreenderia muito mal o pai.Vemos assim como aparece uma mãe cujo desejo é destruído pelo pai, mãe que não se apresenta, no interior do núcleo familiar, como capaz de dar conta do desejo de um homem. Tal destruição do 
desejo materno provoca um problema no plano das identificações. Na questão sobre o que é uma mulher, a mãe não conta para Dora.

Tal perspectiva permite a Freud perguntar-se sobre a função da cumplicidade de Dora em relação a esta situação na qual se enredara. Freud lembra, por exemplo, como ela se ocupava dos filhos da Sra. K, como se procurasse facilitar os encontros do pai. Sua relação com a Sra. K chega a ponto das duas dormirem juntas na mesma cama, à ocasião em que Dora se hospedava na casa dos K, à beira do famoso lago. De fato, é peculiar uma relação na qual uma garota dorme na cama da mulher que ela sabe ser a amante do pai.

Freud insiste que deve existir aqui a reatualização de um processo de identificações que não ocorrera, de maneira satisfatória, no interior do universo familiar nuclear. Ele acredita que tal identificação dizia respeito à relação entre Dora e a Sra. K. A função maternal de matrizidentificatória será suplementada pela Sra. K.

No entanto, a partir da interpretação de Freud, esta seria uma maneira de ocupar o lugar da Sra. K diante de seu marido. Ele insiste várias vezes com Dora que ela está apaixonada pelo Sr. K. Como se um dos fundamentos da histeria fosse encontrado no fato de Dora ser incapaz de admitir e agir a partir da certeza de uma paixão que pareceria evidente a todos. A história desta paixão que não se diz seria, aos olhos de Freud, o preço a pagar para transformar a histeria em uma história.

Poderíamosimaginarque o problema ligado ao reconhecimento de seuamor pelo Sr. K fosse de ordem moral (apaixonar-se por um homem casado). No entanto, ele é de outra ordem. Para Freud, há algo vinculado a certa maturação libidinal que não consegue se realizar. Primeiro, há algo no comportamento de Dora que parece impedir a realização do curso necessário das escolhas de objeto. Freud chega a afirmar que um dos traços característicos da neurose é a incapacidade de satisfazer as "exigências reais do amor". No caso de Dora, isto equivale a dizer, como foi dito antes, que a posição de ser objeto de desejo de alguém a quem ela amasse lhe aparecia como uma experiência insuportável. Como se o desejo da histérica devesse permanecer, necessariamente, em posição de insatisfação, tema que Jacques Lacan explorou de modo sistemático em suas leituras sobre a histeria. No entanto, tal insatisfação do desejo na histeria indica problemas mais complexos. Uma das maneiras de compreender isto consiste em voltar-se à natureza da relação entre Dora e a Sra. K.

Sabemos como sua relação com a Sra. K, que Freud chega a chamar de "inclinação homossexual", mostra como a relação enciumada a outra mulher reveste-se, para a histérica, de uma função formadora. Ela se serve da imagem de outra mulher para suplementar um modo de sustentar-se na feminilidade. Mas há um ponto fundamental pouco explorado pela posteridade psicanalítica. A Sra. K é o suplemento perfeito para Dora não porque ela seria a figura mais 
bem acabada da feminilidade "bem-sucedida", já que se colocaria como objeto do amor de dois homens que causam o desejo de Dora (seu pai e o Sr. K). Na verdade, a Sra. Kéo suplemento perfeito porque, além de também sofrer de histeria e frequentar sanatórios, ela não tem mais relações sexuais com seu marido (ou de não gostar de tê-las, o que demonstram seus sintomas somáticos e dores de cabeça), preferindo ter (e isto não deixa de causar surpresa) um amante impotente, ou ao menos um amante com quem as relações sexuais resumem-se a felações. Ou seja, a Sra. K fornece para Dora uma imagem ideal que, ao mesmo tempo, é a assunção da feminilidade como lugar de constituição de um objeto para o desejo masculino e conservação da prevalência de um modo de gozo oral a respeito do qual Dora não quer abandonar. Sobretudo, a Sra. K não é, para Dora, uma ameaça em relação à oralidade de seu gozo. Desta forma, ela permite a constituição de uma via singular na qual seria possível a realização de si como objeto de desejo de um homem.

No entanto, algo disso se perde para Freud a partir do momento em que ele se coloca na posição daquele que enuncia para a paciente qual o objeto de seu desejo através da insistência em seu amor pelo Sr. K. Ele fornece, de maneira absolutamente expeditiva, a norma na qual o desejo da paciente deve se reconhecer. Não são poucas as vezes em que Freud corta qualquer possibilidade de elaboração, por Dora, de sua própria experiência afetiva, ao nomear, em seu lugar, o objeto de seu desejo. Há algo de muito diferente entre a paciente elaborar, através de sua experiência, a nomeação do objeto de seu desejo e o analista nomeá-lo de forma normativa. Neste caso, a reação do paciente não pode ser vista como alguma forma de denegação, mas como a compreensão de que um objeto só advém necessário ao desejo quando se enuncia no interior da série de contingências que determinaram seu encontro. Assim, o objeto não é o mais importante, mas a rede de relações que construíram seu lugar.

A interpretação de Freud produz um curto-circuito na constituição de tal rede; ele bloqueia seu aparecimento e a elaboração singular de sua constituição (que poderia estar "naturalmente" em vias de se produzir). Se assumisse seu amor pelo Sr. K, Dora o amaria à maneira de Freud, e nunca à sua maneira. Como 0 amor é a elaboração singular de um encontro contingente, não seria incorreto dizer que Freud fez com que toda a paixão pelo Sr. K perdesse o sentido para Dora.

Freud precisa fazer isto para fornecer à Dora a história de seu desejo, uma história de conflitos edípicos não resolvidos. Mas talvez a história de Dora fosse outra, muito mais próxima de demandas não realizadas de reconhecimento e de construções bloqueadas por Dora não saber como afirmá-las. 


\section{SEM LUGAR}

Insistamos ainda sobre outro ponto que nos auxilia na compreensão da natureza necessariamente insatisfeita do desejo de Dora. No decorrer da interpretação de Freud, Dora demonstra ter consciência da natureza da doença de seu pai. Ele era sifilítico e tudo indicava que contraíra a doença antes do casamento. Sua mãe parecia ter sintomas ligados à transmissão da sífilis, como dores no ventre e leucorreia. Na dimensão fantasmática, Dora também se colocava como portadora deste vínculo com o pai, daí sua maneira patológica de vivenciar a sexualidade, em especial a sexualidade genital. Sua histeria poderia assim ser interpretada como sua maneira de participar da doença do pai: "Meu pai estragou a experiência da sexualidade", pensa Dora. "Ele produziu um vínculo indissociável entre sexo e doença. Minha maneira de ser a filha de meu pai, de assumir certa filiação, é perpetuando tal vínculo através da histeria." Jacques Lacan afirmava que a impotência do pai era a chave do problema da histeria de Dora. Podemos seguir esta intuição afirmando que a impotência produzida pela sífilis mostra, para Dora, como a força do desejo pode acabar por destruir a própria possibilidade de realização do desejo.

Note-se como, neste sentido, a verdadeira coordenada social da histeria não aparece como os conflitos produzidos pela moral vitoriana do final do século XIX com a consequente impossibilidade de enunciação do desejo sexual em sua verdade, ou seja, com a consequente impossibilidade do "falar franco" sobre sexo. Ao menos se seguirmos Dora, o problema da histeria está mais claramente ligado à incapacidade da figura paterna dissociar sexo e destruição, ou se quisermos ser mais clássicos, sexo e morte. A experiência do desejo sexual transmitida pela figura paterna não é tranquilizadora, mas é encarnação de um índice de perigo. Por isso, Dora não pode chegar perto demais da assunção de sua própria sexualidade. Ela deve então ficar em um ponto no qual interesse libidinal e gozo permanecem dissociados.

Lembremos como, quando tratada por Felix Deutsche 24 anos depois (DEUTSCHE, s/d), Dora falará compulsivamente sobre sua frigidez e infelicidade conjugal ininterrupta. Ela reclamará do egoísmo dos homens e dirá não poder ter um segundo filho devido ao aspecto traumático das dores de parto que sentiuà ocasião do nascimento de seu primogênito. Os sintomas somáticos continuaram, acrescidos de outros ligados à audição e à constipação.

Estamisériaafetivaligadaàassunçãodaheterossexualidade(frigidez,desgosto dos homens, experiência traumática do parto) não deve levar, necessariamente, a ver, na homossexualidade, uma possível vida afetiva melhor para Dora. $\mathrm{Na}$ verdade, a maneira dessexualizada com que a Sra. Kaparece nas fantasias de Dora (como no sonho onde encontramos a associação entre a Sra. Ke a madona 
de Rafael) ${ }^{3}$ lembra como o problema histérico encontra-se não em alguma forma de confusão de gênero, mas na dificuldade em aproximar vida afetiva e experiência de gozo sexual, qualquer que seja este gozo.

Dora não é uma homossexual que se desconhece enquanto tal, mas alguém que não sabe qual seu lugar como desejante. Ela não está no lugar errado, simplesmente não há lugar possível para ela. Ela está em lugar algum. Como dirá Lacan: "Dora não pode nada dizer sobre o que ela é; Dora não sabe onde se situar, nem onde está, nem para que ela serve, nem para que serve o amor" (LACAN, 1988, p.146). Isto porque talvez seja correto dizer que Dora não sabe sequer o que pode significar uma identidade de gênero, enquanto marcador de um circuito do desejo. Fato que Lacan percebeu muito bem ao afirmar que a histeria é uma questão enunciada da seguinte forma: "O que é uma mulher?".

Lacan insiste, em várias ocasiões, que a neurose organiza-se em torno de uma questão. Esta é uma maneira de dizer que certos sujeitos organizam suas vidas de maneira tal que, em vários momentos, uma mesma questão aparecerá polarizando os conflitos e mostrando como as respostas anteriores eram provisórias. O caráter neurótico da questão se encontra na impossibilidade de o sujeito suportar a ausência de uma resposta decisiva que lhe colocaria, de uma vez por todas, em uma posição existencial assegurada. Por isso, tais questões se transformaram em dispositivo de confrontação constante com o desamparo.

\section{GÊNERO E CONTINGÊNCIA}

Podemos compreender esta incapacidade de Dora em entender o que pode significar uma identidade de gênero lembrando que uma das bases da teoria freudiana da sexualidade é a suposta disposição humana à bissexualidade. Em um pequeno texto de 1908 intitulado "Fantasmas histéricos e a bissexualidade", Freud afirma que um sintoma histérico corresponde necessariamente a um compromisso entre moções contraditórias eque tal contradição pode corresponderà união de dois fantasmas libidinais de caráter sexual oposto. Ele lembra que nãoé raro encontrarmos sintomas de significação bissexual na histeria, o que explica

\footnotetext{
${ }^{3}$ A figura da Madona parece esclarecer a natureza do conflito figurado no sonho. Enquanto mãe virgem, Maria fornece a imagem de um feminino sem sexo, profundamente idealizado e ancorado na maternidade. Note-se ainda que, no quadro de Rafael, Maria está ao lado de São Sixto e Santa Bárbara. Freud não explora esta via, mas Bárbara foi decapitada pelo próprio pai por abjurar a fé cristã. Para isolá-la do contato do mundo, o pai a trancara em uma torre. Mesmo sendo bela, ela recusava todos os pretendentes. Ao perceber a força de sua fé cristã, o pai a entregou ao prefeito, que mandou torturá-la, extirpando seus seios. Como nem isto abalou a fé de Bárbara, seu pai a decapitou. Ou seja, o quadro não deixa de se referir à destruição da filha pelo pai e à impossibilidade de o pai permitir à filha operar suas próprias escolhas.
} 
por que mesmo tratando uma das vertentes do sintoma, ele parece continuar irredutível por se apoiar na vertente sexual oposta.

Mas notemos um dado importante. Se a tese de Freud refere-se a uma disposição geral, de base orgânica, à bissexualidade, há de se perguntar por que na histeria tal disposição aparece de maneira patológica, ou seja, por que esta dualidade é necessariamente vivenciada sob a forma de uma contradição insuperável e fonte de sofrimento psíquico. Uma resposta possível é: porque a histérica não sabe o que é uma identidade de gênero. Assim, sua dificuldade em aproximar vida afetiva e gozo sexual vem, entre outras coisas, do seu vínculo a uma noção degênero fundada na impossibilidade de construções singulares da sexualidade capazes de integrar, na dimensão fantasmática, processos como, por exemplo, a disposição à bissexualidade.

A leitura fornecida por Lacan explora este ponto ao afirmar que há duas vias identificatórias em Dora: a feminina (a mãe, a governanta, a Sra, K) e a masculina (o pai, o Sr. K, o próprio Freud). Estas identificações masculinas seriam marcadas pela agressividade e pela confusão narcísica, já que estão dispostas no nível imaginário (contrariamente às identificações femininas, que estariam no nível simbólico). Elas indicam rivalidade em relação a figuras masculinas (claramente presente na maneira depreciativa de Dora falar dos homens, nesta sua maneira de dizer que os homens não servem para nada), ao mesmo tempo que absorção de alguns traços imaginários (como o ato de fumar, a concorrência intelectual, entre outros) que constituirão seu Eu.

Poderíamos imaginar que Dora teria sido capaz de lidar melhor com sua histeria na medida que pudesse integrar suas reivindicações masculinas no interior de uma relação afetiva, o que exigiria um homem para quem tais reivindicações fosse ocasião de gozo, e não sinais de alguma forma de protestação viril ameaçadora. Isto só seria possível se Dora constituísse escolhas de objeto para além da série produzida pela identificação com o pai. Por outro lado, ela deveria integrar a forte tendência oral de seu gozo, resolvendo o "mistério de sua feminilidade corporal". Difícil imaginar que isso seria possível no interior de um casamento burguês do começo do século XX - o que implicaria aceitar que a pergunta sobre o que é uma mulher simplesmente não pode ser enunciada, já que sua resposta não está em uma elucidação, mas em uma construção.

Talvez a partir daí possamos entender uma afirmação central de Lacan: “a histérica quer o saber como modo de gozo, mas para fazê-lo servir à verdade, à verdade do mestre que ela encarna, enquanto Dora. E esta verdade é, para dizer de uma vez, que o mestre é castrado" (LACAN, 1998, p.110). Ou seja, Dora não quer o gozo, mas o saber sobre a verdade da castração. Saber sobre como a via fornecida pelo pai (epor todohomem queentrarna mesma sériedeidentificações paternas, como o próprio Freud tentou fazer — de onde se segue o problema 
fundamental de sua interpretação) encontra-se inutilizada, pois não há vida afetiva possível para ela aqui. No entanto, este é um saber a respeito do qual ela não sabe o que fazer. Este gozo histérico da castração termina necessariamente no infinito ruim do desvelamento da impotência do mestre, ou seja, revelação da incapacidade de certo tipo de homem saber o que fazer com o desejo de Dora. Tal gozo histérico se realiza apenas na satisfação neurótica de dizer e comprovar insistentementequeoshomensnuncaaentenderamenuncaaentenderão, nunca saberão reconhecer sua feminilidade em toda sua extensão.

Desse modo, a construção do feminino passa pela compreensão de que as posições heterossexuais são menos normativas, rígidas e coerentes do que certas teorias de gênero gostariam de nos fazer acreditar. Admitamos que na base da posição heterossexual há a ideia de que o desejo se deixa tocar pela diferença sexual, de que há uma experiência de diferença queémotor de gozo. No entanto, tal diferença não é apenas externa, mas interna à própria identidade subjetiva. Como se no interior de uma identidade de gênero houvesse uma forma de gozo queéabertura à experiência da diferença, queémarca dos objetos eposiçõesque foram abandonadas na constituição de uma identidade de gênero e na definição de escolhas heterossexuais de objeto.

Noentanto,nadaimpedequeumobjetodeescolhaheterossexual possamuitas vezes aparecer como aquele que permite a construção de um arranjo singular no qual disposições ligadas a estes objetos abandonados encontrarão abrigo. $\mathrm{Na}$ verdade, esta é uma experiência bastante comum e trivial, já que a procura por tal construção é simétrica, ela perpassa os dois sujeitos presentes nas relações heterossexuais. Assim, não há a necessidade de aceitarmos que: "a identificação de gênero é uma forma de melancolia na qual o sexo do objeto proibido é internalizado como uma proibição" (BUTLER, 1999, p.80). A identificação de gênero não é uma forma de melancolia. Esta crença é, na verdade, uma posição histérica por excelência, ou seja, é a histérica quem vivencia tal forma de melancolia de gênero. Na verdade, a identificação de gênero pode aparecer também como conviteà construção singular deexperiências deencontros afetivos contingentes.

Isto demonstra como, quando a histeria desaparece do quadro clínico, há uma dimensão do sofrimento psíquico que deixa de ser tematizada. Sem a histeria, perdemos a possibilidade de tematizar como os sujeitos sofrem por não serem capazes de articular identidade de gênero e contingência (no caso de Dora, a contingência de sua oralidade e da forma peculiar de inscrever sua bissexualidade).

Lembremos, por fim, como, no quadro psiquiátrico atual, sintomas antes associados à histeria aparecem nos transtornos de personalidade histriônica, com seu "padrão global de excessiva emotividade e comportamento de busca deatenção", sua "dramaticidade, teatralidadee expressão emocional exagerada" 
(DSM-IV, 2002, p.664-665). ${ }^{4}$ Assim, a sustentação imaginária dos traços de caráter na histeria perde sua etiologia para deixar advir um problema em si. Operação possível apenas se aceitarmos este exercício bisonho de definição normativa do que pode vir a ser uma "emotividade excessiva" (e, por consequência, uma "emotividade adequada"), uma "dramaticidade exagerada". Há de se perguntar o que é uma "dramaticidade normal", a não ser, simplesmente, aquilo que, como diz o DSM IV, não "embaraça amigos e conhecidos por uma excessiva exibição pública de emoções". Ou seja, aquilo que responde a critérios fluidos de assentimento social.

Outros traços ligados à histeria aparecem, hoje, como transtornos de somatização e transtornos conversivos. A etiologia ligada aos problemas relativos à maturação do corpo libidinal e à construção da experiência da sexualidade desaparece. Em seu lugar temos o transtorno de somatização como "padrão de múltiplas queixas somáticas recorrentes e clinicamente significativas" fundado sobre a bricolagem arbitrária de "quatro sintomas dolorosos, dois sintomas gastrintestinais, um sintoma sexual e um sintoma pseudoneurológico" (há de se perguntar, por que um sintoma sexual e não dois? Por que quatro sintomas dolorosos, e não três?). Desta forma, perde-se mais uma vez a capacidade de pensar como o corpo é capaz de mostrar identidades de gênero como fonte de sofrimento. Por estas e outras razões, reconhecer a permanência funcional da histeria é algo que aparece como justificável.

Recebido em 5/11/2012. Aprovado em 18/3/2013.

\section{REFERÊNCIAS}

AMERICAN PSYCHIATRY ASSOCIATION. (2002) DSM IV - Manual diagnóstico e estatístico de transtornos mentais. Porto Alegre: Artes Médicas.

BADIOU, Alain. (2006) O século. Aparecida (SP): Ideias e Letras.

BUTLER, Judith. (1999) Gender trouble: feminism and the subversion of identity, New York: Routledge. (1994) Bodies that matter. New York: Routledge.

DAVID-MÉNARD, Monique. (1990) A histérica entre Freud e Lacan. São Paulo: Escuta.

DEUTSCH, Felix; Apostila ao "Fragmento de análise de um caso de histeria", de Freud. (mimeo), s/d.

\footnotetext{
${ }^{4}$ Tal transtorno é responsável por algumas das aproximações mais rasteiras da psiquiatria em relação à psicologia popular. Veja, por exemplo, colocações como: "Eles empenham-se excessivamente em impressionar os outros com sua aparência e despendem tempo, energia e dinheiro excessivos para se vestir e arrumar" (DSM-IV, 2002, p.665). Como se vê, uma rica descrição psiquiátrica.
} 
FOUCAULT, Michel. (1976) Histoire de la séxualité. v.l, Paris: Gallimard. FREUD, Sigumnd. (1999) "Brichstuck einer Hysterie-Analyse", in Gesammelte Werke, v.V. Frankfurt: Fischer.

GEYNSKEN, Thomas \& VAN HAUTE, Phillipe. (2012) A non edipical psychoanalysis. Leuven University Press.

LACAN, Jacques. (1966) Ecrits, Paris: Seuil. . (1988)Séminaire IV, Paris : Seuil. (1998) Seminaire XVII, Paris: Seuil.

PLATÃO. (1990) Timée. Paris: Pleiade.

STAROBINSKI, Jean. (2003) Ação e reação, Rio de Janeiro: Civilização Brasileira.

TRILLAT, Etienne. (1986) História da histeria, São Paulo: Escuta.

Vladimir Safatle

vsafatle1@gmail.com 
